\title{
Monosomy 13 in Mammary Myofibroblastoma
}

\author{
IOANNIS PANAGOPOULOS ${ }^{1}$, LUDMILA GORUNOVA $^{1}$, MARIUS LUND-IVERSEN $^{2}$ and SVERRE HEIM ${ }^{1,3}$ \\ ${ }^{1}$ Section for Cancer Cytogenetics, Institute for Cancer Genetics and Informatics, \\ The Norwegian Radium Hospital, Oslo University Hospital, Oslo, Norway; \\ ${ }^{2}$ Department of Pathology, The Norwegian Radium Hospital, Oslo University Hospital, Oslo, Norway; \\ ${ }^{3}$ Institute of Clinical Medicine, Faculty of Medicine, University of Oslo, Oslo, Norway
}

\begin{abstract}
Background/Aim: Myofibroblastoma of the breast is a rare benign mesenchymal tumor whose morphology is similar to that of spindle-cell lipoma. The few hitherto genetically investigated mammary myofibroblastomas have been shown to have had loss of material from chromosome 13 , changes that are also common in spindle-cell lipoma. Our aim was to add to the existing knowledge of genetic aberrations in mammary myofibroblastoma by investigating another such tumor. Materials and Methods: Cytogenetic and array comparative genome hybridization (aCGH) analyses were performed on a surgically removed mammary myofibroblastoma from a 76-year-old man. Results: Shortterm cultured cells from the tumor showed the karyotype 45,XY,-13[3]/44 45,idem,add(19)(q13)[cp2]. aCGH detected loss of one entire chromosome 13 and heterozygous loss from $19 q$ between sub-band $19 q 13.12$ and 19qter. Conclusion: These findings add to the evidence that loss of $13 q$ material is typical of mammary myofibroblastomas.
\end{abstract}

Mammary myofibroblastoma is a rare benign mesenchymal tumor of the breast reported for the first time in 1987 in 11 male and 5 female adult patients as a lesion "largely composed of myofibroblasts arranged in fascicular clusters with interspersed bands of hyalinized collagen" (1). Until 2018, fewer than 90 tumors had been reported (2). In most of the publications (3-12), single cases were described adding to the evidence that these are rare tumors.

This article is freely accessible online.

Correspondence to: Ioannis Panagopoulos, Section for Cancer Cytogenetics, Institute for Cancer Genetics and Informatics, The Norwegian Radium Hospital, Oslo University Hospital, Montebello, PO Box 4954 Nydalen, NO-0424 Oslo, Norway. Tel: +47 22782362, e-mail: ioannis.panagopoulos@rr-research.no

Key Words: Mammary myofibroblastoma, cytogenetics, chromosome 13, deletion.
Genetic information on mammary myofibroblastoma is available for 21 tumors: two were examined by G-banding and karyotyping (10); ten by fluorescence in situ hybridization (FISH) analysis using a probe specific for the forkhead box O1 (FOXO1) gene which maps to chromosome sub-band 13q14.11 (11, 13-15); eight using a FISH probe for the RB transcriptional corepressor 1 ( $R B 1$ located on 13q14.2) gene $(16,17)$; and one tumor was examined by OncoScan as part of a copy-number variant study of 11 benign mesenchymal tumors (18). Because of the rarity of the tumor and the limited genetic information, we present here another mammary myofibroblastoma examined by banding cytogenetics and array comparative genome hybridization (aCGH).

\section{Materials and Methods}

Ethics statement. The study was approved by the Regional Ethics Committee (Regional komité for medisinsk forskningsetikk Sør-Øst, Norge; http://helseforskning.etikkom.no; 2010/1389/REK sør-øst A). Written informed consent was obtained from the patient. The Ethics Committee's approval included a review of the consent procedure. All patient information has been de-identified.

Case Report. A tumor was removed from the breast of a 76-year-old male patient. It measured $5 \times 4 \times 3 \mathrm{~cm}$, had a solid consistency and was well demarcated from the surrounding adipose tissue (Figure 1A). Microscopically, the tumor was partly well demarcated from surrounding adipose tissue in some areas (Figure 1B) but in other areas less so (Figure 1C). The tumor cells were elongated and intermingled with hyaline fibers (Figure 1D). Loosely arranged spindle cells with indistinct cell borders were seen (Figure 1E). Mitotic figures were sparse. Necrosis was not present. No ductal structures were found within the tumor. The tumor's immunohistochemical profile was as follows: Positive markers: Cluster of differentiation 34 (CD34), CD99, and BCL2 apoptosis regulator (BCL2); negative markers: MDM2 proto-oncogene (MDM2), ETS transcription factor ERG (ERG), caldesmon 1 (CALD1), S100 calcium binding protein A1 (S100A1), melan-A (MLANA), cytokeratin AE1/AE3, CD68, KIT protooncogene, receptor tyrosine kinase (KIT), anoctamin 1 (ANO1), epithelial membrane antigen (EMA), mucin 4, cell surface-associated (MUC4), TLE family member 1, transcriptional corepressor (TLE1), SRY-box transcription factor 10 (SOX10), desmin (DES), and actin 
A

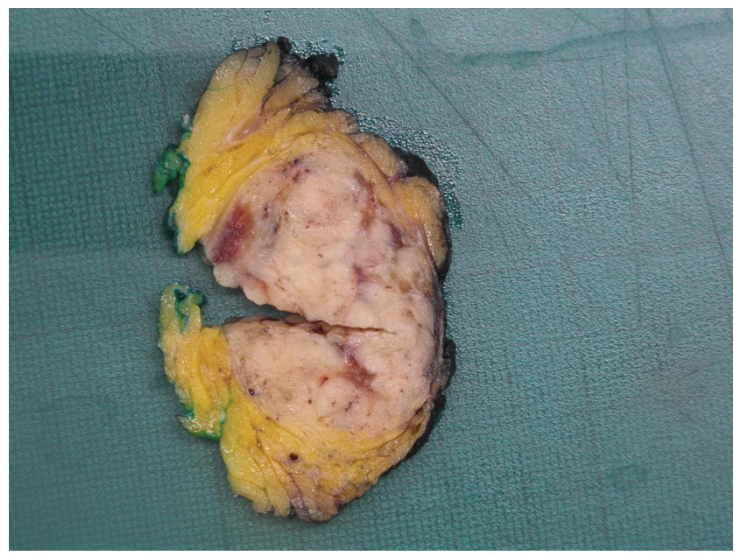

C

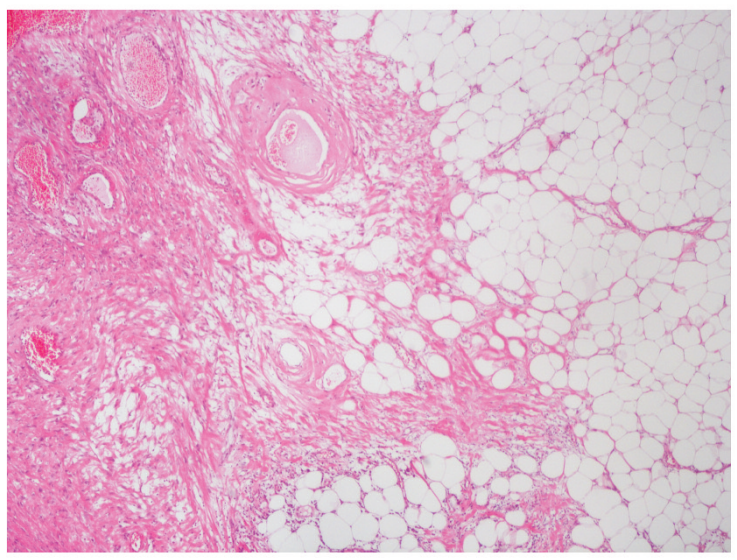

E

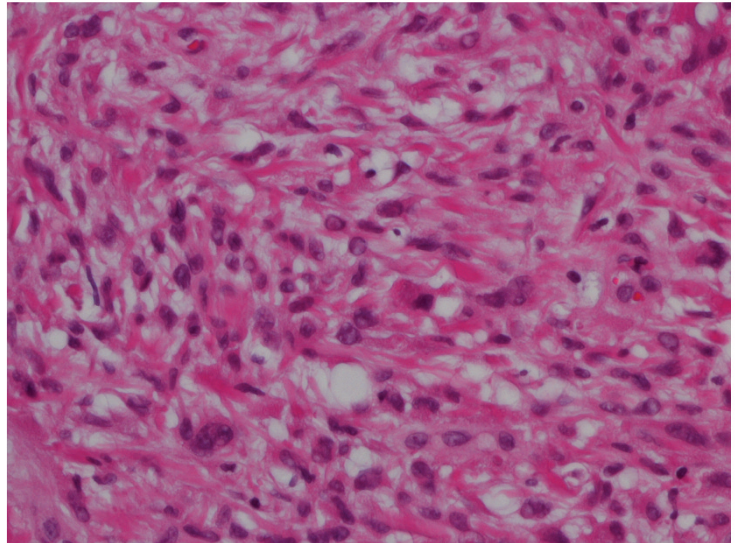

B

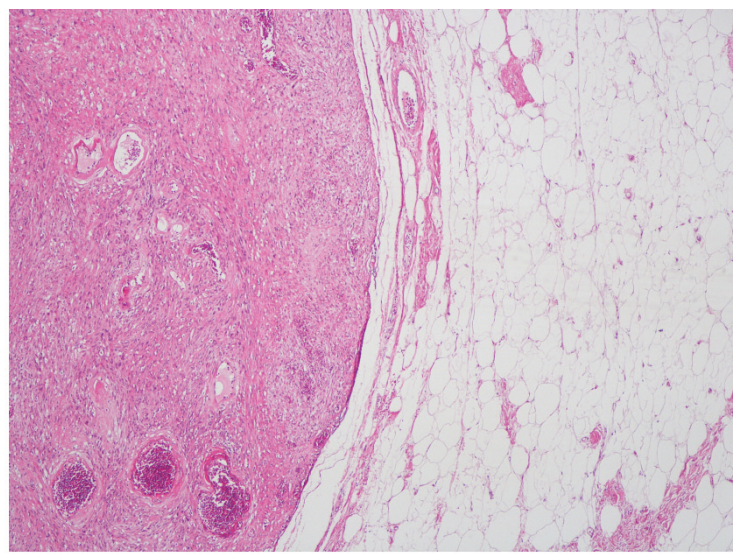

D

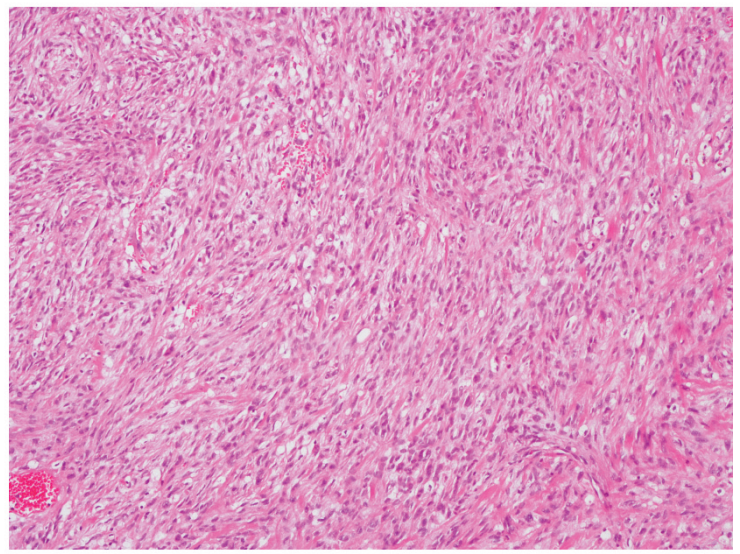

Figure 1. Gross and microscopic images of the mammary myofibroblastoma: A: Gross view in cross section of tumor with surrounding adipose tissue. B: Tumor (left), well demarcated from the surrounding adipose tissue. 40x. C: Area in which the tumor was less well demarcated from the surrounding tissue. 40x. D: Tumor with intermingled hyaline fibers. 100x. E: Loosely arranged spindle cells with indistinct cell borders. 400x.

alpha 2, smooth muscle (ACTA2). Signal transducer and activator of transcription 6 (STAT6) showed cytoplasmatic staining, i.e. the profile did not indicate any fusion of STAT6 with NGFI-A binding protein 2 (NAB2). SWI/SNF-related, matrix-associated, actin dependent regulator of chromatin, subfamily $\mathrm{B}$, member 1 (SMARCB1) was retained. The diagnosis was mammary myofibroblastoma.
Chromosome banding and aCGH. Fresh tissue from a representative area of the resected tumor was used in further analyses. Cells were short-term cultured, harvested and processed for cytogenetic investigation, G-banded, and karyotyped as previously described (19). The methods for aCGH analysis have been described in detail elsewhere (20). 
A

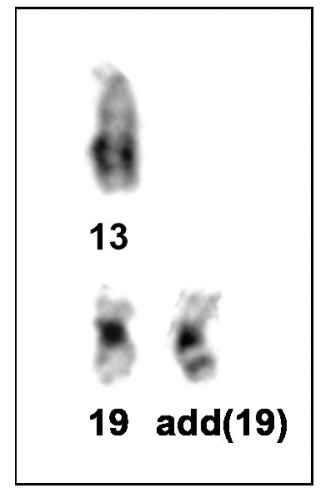

B

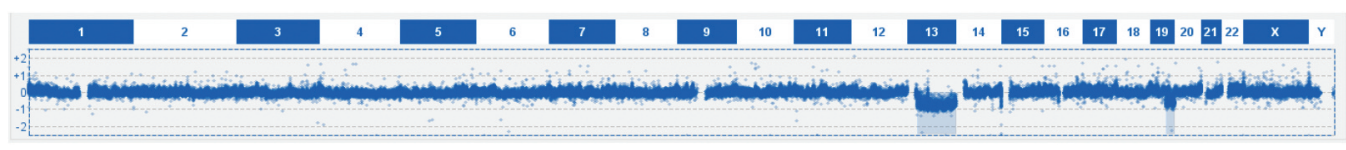

C

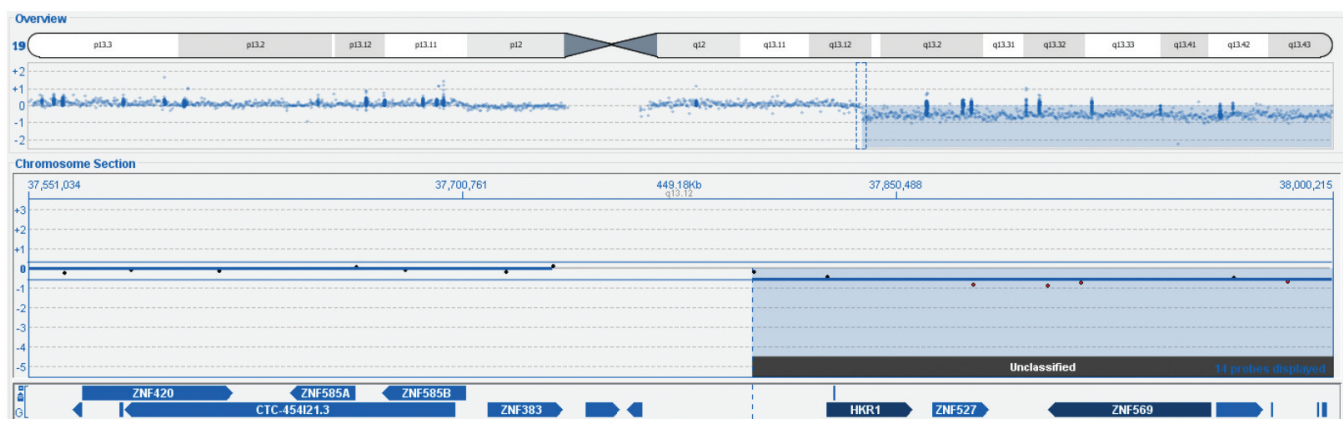

Figure 2. Genetic analysis of the mammary myofibroblastoma: A: Partial karyotype showing monosomy 13 and add(19)(q13). B: Array comparative genome hybridization (aCGH) showing losses of chromosome 13 and material from chromosome arm 19q. C: aCGH showing loss from sub-band $19 q 13.12$ to 19qter, probably corresponding to the additional structural rearrangement, add(19)(q13), seen by G-banding analysis.

\section{Results}

G-Banding analysis of short-term cultured cells from the mammary myofibroblastoma showed chromosomal abnormalities corresponding to two related clones. In the first, loss of one chromosome 13 was seen. The second clone showed monosomy 13 together with a structural rearrangement in which part of the q arm of chromosome 19 had been lost (q13-qter) while additional material of unknown origin was attached to chromosome band $19 \mathrm{q} 13$ (Figure 2A). This corresponded to the following karyotype: 45,XY,-13[3]/44 45, idem, add(19)(q13)[cp2] .

aCGH analysis detected loss of the entire chromosome 13 corresponding to the monosomy 13 seen by G-banding (Figure 2B). In addition, heterozygous loss from sub-band $19 q 13.12$ to 19 qter was found, probably corresponding to the additional structural rearrangement seen in the second clone (Figure 2C). The breakpoint of the deletion was downstream from the zinc finger protein 383 gene (ZNF383).

\section{Discussion}

Mammary myofibroblastomas exhibit morphological as well as (patho)genetic similarities with other benign connective tissue tumors, but perhaps especially with spindle-cell lipoma $(1,3,6,9,10-18,21-23)$. If we dwell on the genetics they have in common, the only two myofibroblastomas reported to date with cytogenetic aberrations both showed loss of material from chromosome 13 (10): one tumor had the karyotype $46, X Y, \operatorname{del}(13)(q ? 12 q ? 32)$, whereas that of the second was $45, X Y, \operatorname{add}(1)(\mathrm{p} 36),-6, \operatorname{del}(13)(\mathrm{q} 14),-\operatorname{der}(16) \mathrm{t}(6 ; 16)$ (p11;p13)del(16)(q12). Furthermore, monoallelic deletions of the forkhead box O1 gene (FOXO1 also known as FKHR, located on 13q14.11) were found in seven out of 10 mammary myofibroblastomas examined genetically with a FISH probe for FOXO1 (11, 13-15). In other studies, monoallelic deletions of the RB transcriptional corepressor 1 ( $R B 1$, located on 13q14.2) gene were found in five out of nine examined mammary myofibroblastomas (16-18); eight of the cases were examined with a FISH probe for $R B 1$ (16, 17), whereas the ninth tumor was examined with OncoScan in a copy variant study (18). The results we present here, i.e., loss of an entire chromosome 13 , which would correspond to monoallelic losses of both FOXI and RBI if that had been studied, confirm the previously reported key role of -13 or other forms of loss of material from $13 \mathrm{q}$ in mammary myofibroblastomas.

A similar loss or deletion pattern has repeatedly been reported not only for spindle-cell/pleomorphic lipomas (19, $24,25)$ but also other benign connective tissue tumors such as cellular angiofibroma $(26,27)$, angiolipoma (28), and pseudoangiomatous pleomorphic/spindle-cell lipoma (29). Additionally, FISH studies have demonstrated heterozygous deletions/losses of the FOXO1/RBI loci in cellular angiofibromas and extramammary and vaginal myofibroblastomas $(13,30-34)$. 
The histopathological similarities among the abovementioned tumors and the fact that they all often display loss of material from chromosome 13 indicates that they share the same or similar pathogenetic mechanisms. The transforming event (the loss of chromosome 13 material or some smaller preceding change) may take place in a common mesenchymal stem cell. The somewhat diverse phenotypic features of tumors sharing the same pathogenetic pathway can be accounted for by assuming that the putative tumor stem cell is already restricted in its differentiation abilities at the time of transformation.

In conclusion, our findings add to the evidence that loss of $13 q$ material is typical of mammary myofibroblastomas.

\section{Conflicts of Interest}

The Authors declare that no potential conflicts of interest exist.

\section{Authors' Contributions}

IP designed and supervised the research, performed analyses, and wrote the article. LG performed cytogenetic analysis. ML-I performed the pathological examination. SH supervised the research and assisted with writing of the article. All Authors read and approved of the final article.

\section{Acknowledgements}

This work was supported by grants from Radiumhospitalets Legater.

\section{References}

1 Wargotz ES, Weiss SW and Norris HJ: Myofibroblastoma of the breast. Sixteen cases of a distinctive benign mesenchymal tumor. Am J Surg Pathol 11(7): 493-502, 1987. PMID: 3037930. DOI: 10.1097/00000478-198707000-00001

2 Khatib Y, Pandey V, Khade AL and Pandey R: Myofibroblastoma of the breast: A rare cause of breast lump in a postmenopausal woman. J Midlife Health 9(1): 47-49, 2018. PMID: 29628731. DOI: 10.4103/jmh.JMH_59_17

3 Bégin LR: Myogenic stromal tumor of the male breast (so-called myofibroblastoma). Ultrastruct Pathol 15(6): 613-622, 1991. PMID: 1799026. DOI: 10.3109/01913129109023191

4 Desrosiers L, Rezk S, Larkin A, Khan A and Li C: Myofibroblastoma of the male breast: a rare entity of increasing frequency that can be diagnosed on needle core biopsy. Histopathology 51(4): 568-572, 2007. PMID: 17880543. DOI: $10.1111 / \mathrm{j} .1365-2559.2007 .02808 . x$

5 Kobayashi N, Oda K, Yokoi S, Kanda H, Hayakawa S, Tang X and Osamura Y: Myofibroblastoma of the breast: report of a case. Surg Today 26(9): 727-729, 1996. PMID: 8883248. DOI: 10.1007/BF00312094

6 Magro G: Mammary myofibroblastoma: a tumor with a wide morphologic spectrum. Arch Pathol Lab Med 132(11): 18131820, 2008. PMID: 18976021. DOI: 10.5858/132.11.1813

7 Mele M, Jensen V, Wronecki A and Lelkaitis G: Myofibroblastoma of the breast: Case report and literature review. Int J Surg Case Rep 2(6): 93-96, 2011. PMID: 22096693. DOI: 10.1016/j.ijscr.2011.02.006

8 Ordi J, Riverola A, Solé M, Sentis M, Velasco M, Bernet M and Cardesa A: Fine needle aspiration of myofibroblastoma of the breast in a man. A report of two cases. Acta Cytol 36(2): 194198, 1992. PMID: 1543005

9 Patel A, Hoda SA and Swistel AJ: Mammary myofibroblastoma in a male: A classic case. Breast J 27(2): 181-182, 2021. PMID: 33482686. DOI: 10.1111/tbj.14163

10 Pauwels P, Sciot R, Croiset F, Rutten H, Van den Berghe H and Dal Cin P: Myofibroblastoma of the breast: genetic link with spindle cell lipoma. J Pathol 191(3): 282-285, 2000. PMID: 10878550. DOI: 10.1002/1096-9896(2000)9999:9999<::AIDPATH635>3.0.CO;2-R

11 Trépant AL, Sibille C, Frunza AM, Simon P and Noel JC: Myofibroblastoma of the breast with smooth muscle differentiation showing deletion of $13 q 14$ region: report of a case. Pathol Res Pract 210(6): 389-391, 2014. PMID: 24629658. DOI: $10.1016 /$ j.prp.2014.01.016

12 Venturelli M, Toss A, Cortesi L, Gambini A, Andreotti A, Cascinu S, Tazzioli $G$ and Moscetti L: Male mammary myofibroblastoma: Two case reports and brief review of literature. Mol Clin Oncol 13(1): 33-37, 2020. PMID: 32454973. DOI: $10.3892 /$ mco.2020.2038

13 Magro G, Righi A, Casorzo L, Antonietta T, Salvatorelli L, Kacerovská D, Kazakov D and Michal M: Mammary and vaginal myofibroblastomas are genetically related lesions: fluorescence in situ hybridization analysis shows deletion of 13q14 region. Hum Pathol 43(11): 1887-1893, 2012. PMID: 22575260. DOI: 10.1016/j.humpath.2012.01.015

14 Magro G, Foschini MP and Eusebi V: Palisaded myofibroblastoma of the breast: a tumor closely mimicking schwannoma: Report of 2 cases. Hum Pathol 44(9): 19411946, 2013. PMID: 23574785. DOI: 10.1016/j.humpath. 2013.01 .018

15 Magro G, Vecchio GM, Michal M and Eusebi V: Atypical epithelioid cell myofibroblastoma of the breast with multinodular growth pattern: a potential pitfall of malignancy. Pathol Res Pract 209(7): 463-466, 2013. PMID: 23707546. DOI: 10.1016/j.prp.2013.04.008

16 Fritchie KJ, Carver P, Sun Y, Batiouchko G, Billings SD, Rubin BP, Tubbs RR and Goldblum JR: Solitary fibrous tumor: is there a molecular relationship with cellular angiofibroma, spindle cell lipoma, and mammary-type myofibroblastoma? Am J Clin Pathol 137(6): 963-970, 2012. PMID: 22586056. DOI: 10.1309/AJCPQEG6YNN6CNAL

17 D'Alfonso TM, Subramaniyam S, Ginter PS, Mosquera JM, Croyle J, Liu YF, Rubin MA and Shin SJ: Characterization of CD34-deficient myofibroblastomas of the breast. Breast J 24(1): 55-61, 2018. PMID: 28557150. DOI: 10.1111/tbj.12835

18 Dusenbery AC, Davick JJ, LeGallo RD and Williams ES: Chromosomal microarray analysis of benign mesenchymal tumors with RB1 deletion. Hum Pathol 102: 88-93, 2020. PMID: 32800346. DOI: 10.1016/j.humpath.2020.06.005

19 Panagopoulos I, Gorunova L, Lund-Iversen M, Andersen K, Andersen HK, Lobmaier I, Bjerkehagen B and Heim S: Cytogenetics of spindle cell/pleomorphic lipomas: Karyotyping and FISH analysis of 31 tumors. Cancer Genomics Proteomics 15(3): 193-200, 2018. PMID: 29695401. DOI: 10.21873/cgp. 20077 
20 Panagopoulos I, Gorunova L, Andersen K, Lund-Iversen M, Lobmaier I, Micci F and Heim S: NDRG1-PLAG1 and TRPS1$P L A G 1$ fusion genes in chondroid syringoma. Cancer Genomics Proteomics 17(3): 237-248, 2020. PMID: 32345665. DOI: $10.21873 /$ cgp. 20184

21 Eyden BP, Shanks JH, Ioachim E, Ali HH, Christensen L and Howat AJ: Myofibroblastoma of breast: evidence favoring smooth-muscle rather than myofibroblastic differentiation. Ultrastruct Pathol 23(4): 249-257, 1999. PMID: 10503744. DOI: 10.1080/019131299281581

22 Magro G: Mammary myofibroblastoma: an update with emphasis on the most diagnostically challenging variants. Histol Histopathol 31(1): 1-23, 2016. PMID: 26328916. DOI: 10:14670

23 Metry M, Shaaban M, Youssef $M$ and Carr M: Myofibroblastoma of the breast: Literature review and case report. Case Rep Oncol Med 2016: 1714382, 2016. PMID: 27525142. DOI: $10.1155 / 2016 / 1714382$

24 Dal Cin P, Sciot R, Polito P, Stas M, de Wever I, Cornelis A and Van den Berghe H: Lesions of 13q may occur independently of deletion of $16 \mathrm{q}$ in spindle cell/pleomorphic lipomas. Histopathology 31(3): 222-225, 1997. PMID: 9354891. DOI: 10.1046/j.1365-2559.1997.2450851.x

25 Bartuma H, Nord KH, Macchia G, Isaksson M, Nilsson J, Domanski HA, Mandahl N and Mertens F: Gene expression and single nucleotide polymorphism array analyses of spindle cell lipomas and conventional lipomas with 13q14 deletion. Genes Chromosomes Cancer 50(8): 619-632, 2011. PMID: 21563233. DOI: $10.1002 / \mathrm{gcc} .20884$

26 Hameed M, Clarke K, Amer HZ, Mahmet K and Aisner S: Cellular angiofibroma is genetically similar to spindle cell lipoma: a case report. Cancer Genet Cytogenet 177(2): 131-134, 2007. PMID: 17854668. DOI: 10.1016/j.cancergencyto.2007.05.016

27 Panagopoulos I, Gorunova L, Bjerkehagen B, Andersen K, Lund-Iversen M and Heim S: Loss of chromosome 13 material in cellular angiofibromas indicates pathogenetic similarity with spindle cell lipomas. Diagn Pathol 12(1): 17, 2017. PMID: 28193293. DOI: 10.1186/s13000-017-0607-6
28 Panagopoulos I, Gorunova L, Andersen K, Lobmaier I, Bjerkehagen $\mathrm{B}$ and Heim S: Consistent involvement of chromosome 13 in angiolipoma. Cancer Genomics Proteomics 15(1): 61-65, 2018. PMID: 29275363. DOI: 10.21873/cgp.20065

29 Panagopoulos I, Gorunova L, Lobmaier I, Andersen HK, Bjerkehagen B and Heim S: Cytogenetic analysis of a pseudoangiomatous pleomorphic/spindle cell lipoma. Anticancer Res 37(5): 2219-2223, 2017. PMID: 28476785. DOI: 10.21873/ anticanres. 11557

30 Flucke U, van Krieken JH and Mentzel T: Cellular angiofibroma: analysis of 25 cases emphasizing its relationship to spindle cell lipoma and mammary-type myofibroblastoma. Mod Pathol 24(1): 82-89, 2011. PMID: 20852591. DOI: 10.1038/modpathol.2010.170

31 Maggiani F, Debiec-Rychter M, Vanbockrijck M and Sciot R: Cellular angiofibroma: another mesenchymal tumour with 13q14 involvement, suggesting a link with spindle cell lipoma and (extra)mammary myofibroblastoma. Histopathology 51(3): 410-412, 2007. PMID: 17727484. DOI: 10.1111/j.1365-2559.2007.02775.x

32 Maggiani F, Debiec-Rychter M, Verbeeck G and Sciot R: Extramammary myofibroblastoma is genetically related to spindle cell lipoma. Virchows Arch 449(2): 244-247, 2006. PMID: 16715228. DOI: 10.1007/s00428-006-0228-z

33 Magro G: Chromosome 13q14 deletion in a mammary-type myofibroblastoma of the big toe-Reply. Hum Pathol 46(2): 344345, 2015. PMID: 25522927. DOI: 10.1016/j.humpath. 2014.10.025

34 Wyn I, Debiec-Rychter M, Van Cleynenbreugel B and Sciot R: Cellular angiofibroma of the prostate: a rare tumor in an unusual location. Case Rep Pathol 2014: 871530, 2014. PMID: 25105048. DOI: $10.1155 / 2014 / 871530$

Received May 24, 2021

Revised June 15, 2021

Accepted June 22, 2021 